\title{
Semiotic pollution: Deliberations towards an ecology of signs
}

\author{
Roland Posner \\ Technical University Berlin, \\ Ernst-Reuter-Platz 7, D-10587 Berlin, Germany \\ e-mail: posn0135@mailszrz.zrz.tu-berlin.de
}

\begin{abstract}
This article compares the material pollution of life's elementary resources, i.e., water, soil, and air, with the semiotic pollution of the elementary resources of sign-processes, i.e., channel, sign-matter, and message; code, signifier, and signified; as well as context, sender, and recipient. It is claimed that semiotic pollution interferes with sign-processes as much as material pollution interferes with the fundamental processes of life; both types of pollution are similar in that they produce stress for human beings in current societies. It is argued that semiotics is able to provide the conceptual tools necessary to develop policies that can reduce semiotic pollution. As is shown, however, additional research is required to operationalize and metricize generalized concepts of semiotic pollution such as "channel-related", "semiosis-related", and "situation-related noise".
\end{abstract}

Since the 1960s, there has been much talk about the ever increasing constraints that environmental pollution places on our quality of life. In recent decades, ecology has worked hard to explicate the notion of pollution scientifically and to render objectively measurable the degree to which a biotope is polluted (Weizsäcker 1989). This article attempts to show that this concept of pollution is insufficient to explain important causes of the constraints placed on our quality of life. The common idea of material pollution, therefore, is to be augmented by the concept of semiotic pollution. In this article, a suggestion for the explication of this concept is developed and possible means of 
objectively measuring the degree of semiotic pollution are considered. Given the current status of research, the goal of this paper is not to present a fully elaborated theory of semiotic pollution, but rather to open the discussion of the possibilities and limits of such a theory. In providing this discussion with the necessary concepts, semiotics accepts social responsibility for its objects of research.

\section{Material pollution}

Today, those who speak of pollution mean

- the poisoning of rivers, lakes, and seas with industrial waste and fertilizers (Dorst 1998),

- the contamination of the soil with heavy metals and pesticides (Lagadec 1987; Reiser and Martzloff 1988), and

- the smogging of the air with industrial and automotive emissions (Koch 1983; Wolf 1988).

Citizens of industrialized countries are subject to a considerable amount of stress due to these developments since they place constraints on their activities (Selye 1976; Jerusalem 1990). One personally experiences the reduction of the quality of life, when one can no longer

- drink tap water for fear of stomach problems,

- swim in a river, lake, or sea for fear of exposure to contagious diseases,

- eat the fruit and vegetables from one's own garden for fear of ingesting high doses of heavy metals,

- stay out in the sun for extended periods of time for fear of getting skin cancer due to overly powerful ultraviolet rays,

- breathe fresh air for fear of heart problems due to the high ozone content.

Stress, however, is also caused when one leaves the house and cannot

- go anywhere without running into fences and traffic signs,

- avoid seeing billboards and signs wherever one looks,

- read the advertisement texts because there are too many of them,

- recognize the faces of people in traffic because their eyes are hidden behind helmets and sunglasses,

- understand what someone is saying because the traffic noise drowns them out, 
- smell the rejuvenating aroma of the trees lining the streets because it is masked by the exhaust from the air conditioners;

- taste the natural aroma of a meal because the ingredients are grown in a greenhouse, neutralized with conservatives, and treated with aroma enhancers (Posner 1998).

For the past generation, environmentalists have called attention to the worldwide deterioration of living conditions. Their campaign has made clear that this development was caused by exactly those measures which were originally taken to improve the standard of living in industrialized countries (Carson 1962, and others).

Environmentalists consider the worst sort of pollution to be the contamination of life's fundamental resources: water, soil, and air (Reiser, Martzlof 1988). This pollution becomes threatening when it disturbs basic life-sustaining processes such as eating, drinking, and breathing.

In general, pollution does not become evident until it is almost too late to repair the damage: it is too late when people taste it in the water, when they see the withered plants in the field, when they have to hold a cloth to their nose because of the stench in the air (Kur 1986). Even if possible, it could take decades or centuries to rid the ground water of chemical substances, to clean the salty, pesticide-contaminated, acidic, or over-radiated soil, and to remove poisonous gases from the air.

The contamination of these resources has occurred insidiously (Böhret 1990). People initially react to the gradual deterioration of their living conditions with subconscious adaptation. When the situation eventually becomes unbearable, they are forced to evacuate the region with poisoned ground water, contaminated soil, and smoggy air.

In the conventional sense, therefore, pollution is a physical deterioration of life's elementary resources through contamination. Pollution is considered a threat because

- it endangers the basic life-sustaining processes of human beings and other higher life-forms,

- it occurs insidiously and is not detected until it is nearly too late to repair the damage,

- exactly those production and consumption processes originally intended to make life easier, paradoxically, wind up making people's lives more difficult. 


\section{Semiotic pollution}

The explosive combination of the threatening factors presented above no longer affects only the basic life-sustaining processes such as eating, drinking, and breathing. Today, it also affects the more advanced needs which people satisfy in interaction with each other. Citizens of highly developed countries become frustrated when

- they look in their mailbox in the morning and find that their important mail gets lost in a flood of advertisements,

- sitting down at their computer, they find hundreds of unsolicited e-mails waiting to be answered before they can begin their work,

- they are forced to call an agency or administrative office and the phone is continuously either busy or unattended or the answering machine is turned on,

- they want to take action and constantly have to consult a lawyer about legal obstructions and risks,

- they want to apply for a job and are obligated to fill out a questionnaire with dozens of irrelevant questions,

- they are forced to sign a contract of purchase and have to read many pages of small print referring to situations which do not apply to themselves,

- they are prescribed medication and the information in the package is not only difficult to understand but also makes note of innumerable non-applicable uses, risks, and side-effects.

In our society, almost all innovations introduced to make life easier end up achieving exactly the opposite; they make our lives more complicated and more difficult. Just as disturbing as the hindrance of fundamental life-processes caused by material pollution is the hindrance of the fundamental sign-processes caused by the pollution of our semiotic resources. It seems justifiable, therefore, to speak of semiotic pollution as being analogous to the material environmental pollution.

Similar to material pollution, semiotic pollution is considered threatening because

- it endangers the fundamentals of human interaction in industrialized countries,

- it occurs insidiously and is not detected until it is nearly too late to repair the damage, and

- exactly those semiotic processes originally intended to facilitate human interaction, paradoxically, wind up hindering it. 
These are far-reaching claims. In the following sections, these claims are first systematized to render them debatable and then are substantiated with reference to examples. The structure of sign-processes and their associated cultural techniques serve here as a guide. The considerations lead to conclusions for the theoretical and empirical research that is necessary for an ecology of signs (Nöth 1996). This, in turn, will make a well-focused semiotic environmental protection policy possible.

\section{Factors of semiosis as semiotic resources and the pollution of these resources}

A complex interpersonal sign-process (semiosis) begins with a sender who, in a given context, communicates a message to an addressee. This is done by using an appropriate channel and by selecting from a common code a signified befitting the message. The signified is connected by means of the code to a signifier that is realized by producing appropriately formed sign-matter. If all of this occurs as the sender intended, the addressee perceives the sign-matter through the channel and recognizes it as a signifier which, due to the code, refers to a signified. Given the signified and the context of transmission, the addressee then reconstructs the message (Posner 1989: 245). In general, the processes involved take place sequentially or, to some extent, simultaneously: the message to be sent must be known in order to select an appropriate signified; the signified must be known in order to identify a signifier; the signifier must be known in order to produce the sign-matter. Thus, the formulation process requires the transformation of a message into a signified, a signified into a signifier, and a signifier into sign-matter. The reception process occurs in the opposite order. It requires the transformation of sign-matter into a signifier, a signifier into a signified, and a signified into the message, which, if there were no disturbances, is the same as the message intended by the sender. The transformations are of quite different types. The sender's transforming the message into a signified and the recipient's transforming the signified into the message are both context-dependent pragmatic processes of abduction (Wirth 1995). The same holds true for the sender 's production of sign-matter when realizing the signifier as well as the recipient's reconstruction of the signified from this signmatter. In contrast, relating the signifier to the signified, as the sender 
does (encoding), and relating the signified to the signifier, as the recipient does (decoding), are semantic processes of deduction (Prieto 1972: 23).

As this outline shows, each sign-process can be described by characterizing the factors involved: sender, recipient, context, channel, sign-matter, message, and code with its signifiers and signifieds. In comparing material and semiotic pollution, it makes sense to regard these factors as resources of the sign-process.

Each of these resources can be polluted (cf. Prieto 1972: 50-58 and 1975: 49-60 on success and failure of communication acts):

- Excessive noise-levels (see section 5 below) in the channel prevent the recipient from recognizing the sign-matter produced by the chosen sender. This obviates all further sub-processes.

- Even if the noise does not reach this point, it can pollute the signmatter to the extent that it loses its conciseness. In the case of codeless semiosis (Posner 1997: 234), this hinders the recipient in ascertaining the message. In the case of coded semiosis, the recognition of the signifier is hampered and with this, all further subprocesses up to the ascertaining of the message must fail.

- The signifier can also become polluted. In such a case, its form cannot be distinguished from other signifiers of the same or of a different code.

- A polluted signified has no clearly defined relationship to the other signifieds of the code and is, therefore, poorly suited for the reconstruction of meaningful messages.

- A message is polluted, when it does not easily correspond to signifieds or apply to the semiosis-partner's context.

- The code is polluted either when its signifiers (syntactic space) or its signifieds (semantic space) are polluted or when the correlation between the syntactic and semantic spaces is muddled (Prieto 1972: 45 and 1975: 27 speaks of "sematic" and "noetic fields"). The latter case exists when there are too many signifiers with more than one signified (homonyms) in the code.

- The context is polluted, when the semiosis-partners either take very different situations into consideration or structure their shared situation differently in translating between the message and the signified (or between the message and the sign-matter in the case of codeless semiosis). It is often unclear to the semiosis-partners which circumstances should be considered as part of the formulation and reception contexts. As a result, the sender does not know 
which signified s/he should select for the message and the recipient does not know which message s/he should derive from the signified.

- Even the sender and the recipient can be polluted. This is the case when they are unable to use the necessary channel or code or to assume the correct context.

As with material resources, the pollution of semiotic resources can, to a certain degree, be compensated by switching over to other resources of the same or different type:

- Surrounded by a din, one switches from the auditory channel to the visual channel to produce gestures rather than to speak.

- When there is a high level of noise, one articulates the sign-matter very carefully so that the signifiers are recognized despite the noise.

- When a signifier is easily misunderstood, one increases the number of signifiers so that they provide additional clues for the decoding process.

- When the signified is unclear, one draws the recipient's attention to a clarifying context.

- When the usual code is muddled in the intended semantic field, e.g., because the usual code was never used in handling the given topic, one switches to a different code.

- When it is probable that the sender and the recipient assess the context of the sign-process differently, then one chooses expressions that can be interpreted independent of the context, i.e., one formulates more explicitly and thereby increases the number of communicated signifieds.

- When one considers the semiosis-partner to be less capable of semiosis, then one lets the situation speak for itself.

\section{Two examples of channel pollution: light and sound}

The analogy between material and semiotic pollution can easily be elaborated in detail for the sign-channels. This is facilitated by the fact that material resources such as air and water are often used as signchannels themselves.

A channel serves to transmit the sign-matter; were the channel itself to become sign-matter, the sign-process would fail. The same 
holds true for material resources; they usually go unnoticed as long as they allow life-processes to take place without a problem. In general, air is odourless, water is tasteless, and both are colourless; that is, unless they contain foreign particles. It is not until the contamination reaches a certain level that the air "smells", the water "tastes of something", and both look "dirty". The air and water pollution can increase to the extent that it disrupts the visual, olfactory, and gustatory perception of other objects. This is the case with smog and auto-exhaust in the air and with oil and chemicals in the water. The strain on the material resources, therefore, has a negative effect on those sign-processes that use these resources as channels. Not only a few but rather all signprocesses which depend on the polluted channel are disturbed.

In modern industrial societies, smog disturbs the visual channel, industrial noise disturbs the auditory channel, and auto-emissions disturb the olfactory channel. The smog, noise, and stench are caused, respectively, by the carbon-dioxide emission of heating systems, the sounds of mechanical production processes, and the exhaust systems of automobiles. All three are examples of materially induced (material and) semiotic pollution. However, the opposite case is also possible: a channel can become semiotically strained resulting in material pollution. Examples of semiotically induced material (and semiotic) pollution are certain types of pollution through light (Schmauks 1997) and through sound (Honkasalo 1996).

The history of natural and artificial light is proof of how technology, in attempting to get rid of a deficiency, winds up helping to produce an overabundance that reaches damaging proportions. For a long time, people's spatial and temporal range of activity was limited because most of their actions could only be carried out in daylight. The art of making and maintaining fire then made nighttime and closed spaces as accessible to sign-processes as was daytime. For thousands of years, however, fire-based light sources, such as wood chips, candles, and oil-lamps, remained so expensive that the majority of people continued going to bed as soon as it got dark. It was not until the end of the nineteenth century that relatively inexpensive electricity made it possible in much of the world to disengage every-day activities from daylight. In all industrial countries today, the cities are lit all night and the basements are supplied with electrical light; visual sign-processes no longer have spatial and temporal constraints. These have been replaced, however, by semiotic constraints. 
The introduction of electric light to enhance visual perception increased the energy consumption. This necessitated the construction of coal and oil power plants, and they, in turn, polluted the air, thus affecting the visual channel. More important, however, the excessive use of light itself has become a problem. Light, which is otherwise needed to see particular objects, becomes visible as such at night and is then often considered a disturbance. Dispersed light disturbs astronomers in their work since almost no stars are visible near large cities. Flocks of migrant birds lose their orientation when in the vicinity of a lit up city. Insects are attracted to luminous sources; if they are not singed by the heat of the lights, they are at least distracted from searching for food and partners. The price of people's increased freedom of motion due to light is, paradoxically, an impoverishment of their visual perception. In the cities, many children grow up without having ever seen a clear starlit sky and the only time many adults have seen the Milky Way is in a planetarium.

The excessive use of electric light not only makes visual signprocesses possible but it also hinders them (light pollution). In the same way, a high concentration of auditory sign-processes can produce the opposite of the intended effect (sound pollution). When walking through a Tunisian village at night, one is annoyed by the incessant barking of dogs. Many people own dogs to warn them of burglars; the dogs are intended to increase security. This, however, becomes impossible as the number of dogs grows larger; there is always a dog barking somewhere and the reason cannot be that burglars are constantly appearing. The continuous barking not only disrupts other auditory sign-processes but also interferes with its own purpose: a constant warning signal is not taken seriously as such.

In this case, one can speak of semiotically induced sound pollution. Based on the sign-behaviour of the dogs, it not only causes a locally restricted disruption of individual sign-processes but produces a constant disturbance of the auditory channel. One cannot escape this disturbance without leaving the country (or at least the affected neighbourhood). This disturbance developed progressively as the canine population grew. Having reached the present level, it can hardly be reduced without really giving burglars the feeling that they can become more active.

The same holds true for traffic noise in Indian metropolitan areas. There are many types of signals to help people orient themselves in traffic: the pedestrian's whistle, the bicycle's bell, the moped's and 
motorcycle's hand-operated horn, the car's and truck's far reaching electric horns, and sometimes even the locomotive's steam whistle. These signals may be distinguishable to the motorists, but to the residents they contribute to a constant din that prevents them from hearing themselves speak. As with the barking dogs in the Tunisian village, this initially successful form of semiosis has become impossible due to its constant rather than intermittent occurrence. Individually, each of these signals can function as a warning signal. When produced simultaneously, however, their mutual disruption causes them to fail as warning signals; and this in turn, produces a great amount of stress. Here too, the current situation developed gradually and is apparently difficult to change without causing the traffic system to collapse. The only way to escape the noise permanently is to leave the city.

The traffic noise caused by the many warning signals is also semiotically induced pollution. This assessment is supported by the noted effect that the traffic noise has on municipal property value. The real estate market reacts to the reduced quality of living by decreasing the property value. Its reactions to material pollution (e.g., oil in the ground water) and to semiotic pollution (e.g., warning signals in traffic) are the same. As with material pollution, semiotic pollution is the worst in the areas where the poorest people live.

The same situation exists in large European cities. Here, however, remedial measures have been taken. Since the 1970s, if the laws enacted to limit acoustic signals are insufficient to reduce the level of traffic noise, then noise barriers are built. While solving one problem, however, this measure produces another: noise barriers are also visual barriers (Rohrmann 1984: 198). In addition to having been robbed of their former peace and quiet, the affected residents are also robbed of their former view of the surrounding area. The relief of the auditory channel results in a disruption in the visual channel. Those who seek visual diversity in spite of this are forced to turn to the "new media" in their own homes: television and video. In this manner, one environmentally disruptive measure leads to another and there is no end in sight to the medial arms race (Bouissac 1993).

Environmental protection measures of this type are also to be found in the other channels. The initially hailed shift in suburban traffic from air-polluting buses to streetcars or trolley busses necessitated the construction of overhead contact lines. The tourists who use the traffic system to see historical buildings and monuments, however, feel cheated because the chaos of the overhead contact lines impairs 
the view of the monuments and destroys their historical context. In this case, the shift is from olfactory channel pollution to visual channel pollution with additional destruction of the sign context. Remedial measures, such as installing mirrors to defer the view from the chaos of wires, are no solution since these only help photographers and simply increase the number of disruptive artifacts.

Such practices are ridiculous. They make about as much sense as installing a refrigerator in an Eskimo's home in order to neutralize the negative effect that the recently introduced central heating system had on food preservation.

These examples show that the visual, auditory, and olfactory (as well as the gustatory and tactile) channels are fundamental semiotic resources. The pollution of these resources reduces our quality of life. The same can be proven for the other factors of semiosis. Space limitation, however, prohibits a continued analysis here.

The semiotic resources of the sign-processes discussed can be compared to the material resources of life-processes as follows.

(1) Material and semiotic resources are both hardly noticed as long as they are not polluted.

(2) The pollution of a material resource (e.g., smog, industrial noise, and auto-emissions) can directly result in the pollution of the respective semiotic resource and vice versa (as in the cases of light and noise pollution).

(3) A polluted material resource impairs not only certain individual life-processes but rather all life-processes of the same type; in the same manner, a polluted semiotic resource impairs not only individual sign-processes but rather all sign-processes which use that resource.

(4) The negative effects of material and semiotic pollution can be reduced to a certain extent by switching to other resources; in this way, however, the pollution frequently spreads from one resource to another.

(5) No higher forms of life can exist if all material resources are completely polluted; and, similarly, no sign-processes are possible where all semiotic resources are totally polluted. 


\section{Research requirements: The investigation of channel-related, semiosis-related, and situation-related noise}

The previous section makes clear that the increased levels of stress which bother people in today's densely populated regions of the world are due to semiotic pollution as much as to material pollution. To alleviate this stress it does not suffice simply to call attention to extreme examples of pollution or to protest only against those instances that affect one personally. Comprehensive criteria for action must be developed if there is to be an end put to the Band-Aid treatment of symptoms and the transfer of pollution from one resource to the next. In principle, semiotic pollution as well as material pollution can be identified objectively. Important is the development of a reliable means of measuring the pollution level in each individual resource (each semiosis factor) as well as its relative contribution to the overall level of pollution. This groundwork is needed, for example, to decide when it makes sense to strain one resource in order to relieve another.

Having to deal with polluted semiotic resources causes stress (Mayer 1979: 235). The goal is to reduce this stress. Measures of pollution must be introduced in such a way that they can be used as a basis for determining the amount of pollution-induced stress (cf. Lazarus 1990 regarding the measurement of stress), depending on the individual circumstances of the people involved (Jerusalem 1990). Regarding all these questions, there is a considerable need for research; at present, semiotic pollution research lags far behind material pollution research.

Responsible for this is, on the one hand, the wide-spread tendency to reduce all problems down to what is physically and chemically measurable and, on the other hand, the conceptual isolation of the subphenomena from one another. Still lacking today are sufficiently detailed models which allow (1) measuring the level of pollution of the various semiotic resources, (2) comparing these measurements, (3) determining their relative contribution to the total semiotic pollution, and (4) identifying threshold values. As Helmar Frank (2001) shows, the work of information theory in the area of cybernetics in the 1960s and 1970s laid important groundwork and information psychology made a series of applications possible. Since then, however, the remaining gap in the research needed to meet the requirements of se- 
miotic environmental protection has hardly become smaller. This is true not only for determining the pollution level of semiotic resources which are as complex as sender, recipient, sign-matter, and context, but also of resources such as codes and channels, which have been relatively well studied in the framework of information theory.

What is needed can be explained with reference to the example of the channels. Information theory tries to measure channel pollution (see section 3 above) using the concept of noise. Noise is the contamination of the channel with sign-matter not stemming from the sender that was chosen by the recipient (Cherry 1967: 245). Examples of noise taken from the technical media are the cracking sounds in the telephone, the atmospheric disturbance in the radio (made noticeable by changes in the volume and distortions of the signifier), and the snow on the television screen.

A high level of noise means that the respective channel is highly strained by interfering sign-matter. This, in turn, indicates a large contribution to the overall level of semiotic pollution (see section 4 above). Aside from light and sound pollution, every-day examples of high channel-related noise levels are the aggravation of the olfactory and gustatory senses, and skin irritation (e.g., due to synthetic materials).

It is a common assumption that semiotic strain on the environment increases proportionately with the number of channels and the degree to which they are strained (Frank 1969). It should be noted, however, that not every increase in a given channel's noise level and not every increase in the number of highly strained channels increases the overall stress experienced by the individual (Lazarus, Folkman 1984):

- Showing a television transmission in a train station definitely increases the strain on the visual channel of the passengers waiting. The transmission of a soccer game can, however, lead to a reduction of their overall stress because it temporarily distracts them from the chaotic activities of other arriving and departing passengers.

- The endless flow of background music in an office or in a department store strains the auditory channel. It can, however, create a relaxed atmosphere which helps the people present to better deal with other types of stress.

- Similarly, perfume affects the olfactory channel. But it can be used to mask unpleasant body odours. 
- At a restaurant, a special mixture of seasonings can make somewhat stale ingredients acceptable to the gustatory demands of the dinner guest.

- In a clinic, nurses are used to suddenly apply pressure with their hand in order to distract the patient from the prick of the needle.

When a signal appears in a channel and covers up another signal in the same channel, it is said that the first signal masks the second. The list above presents examples of visual, auditory, olfactory, gustatory, and tactile masking (Loeb 1986: 48-79). Masking can prevent one from perceiving sign-matter that produces stress. Despite the additional loading of the channel, masking can reduce overall stress.

The different effects that desirable and disturbing masking can have on a person's level of stress show that simply analyzing the noise level in the channel does not suffice to determine the semiotic straining caused by unintended sign-matter. In order to determine the level of semiotic stress one must take into consideration not only the noise level but also the type of noise.

One must also address the question of whether the maskings occur only in specific instances (such as skilled hospital staff giving a shot) or if they occur constantly in order to hinder the perception of a certain type of noise. An example of constant masking is the continuous background music in department stores, public transportation systems, and open-area offices (Korn 1975, Fehling 1976, Körner 1979). In open-area offices, masking may have a positive side-effect on employees: others cannot hear what is being said in a conversation so that, despite the visual transparency of the situation, the interlocutors can enjoy a certain amount of auditory privacy. However, no background music is one-hundred percent emotionally neutral; each person present is subject to the music, whether s/he wants to be or not. Those who do not want to or cannot be soothed, or those who require maximum auditory differentiation and, therefore, need their own beat must be extremely annoyed by all background music (Mayer 1979: 226). The unwanted introduction of foreign signs into a channel that one needs completely for the recognition of intended signs, combined with the impossibility of escaping the situation, turns background music for these people into a classic case of semiotic pollution.

It makes sense to extend the concept of masking to refer also to the interference between signs of different channels (Loeb 1986: 48). Thus, semiotic stress cannot be determined solely on the basis of noise in just one channel. Sign-matter that does not stem from the recipi- 
ent's chosen sender can also reach the recipient via a channel other than the chosen one and, in this manner, affect the reception of the intended signs. A student's communication with an instructor in a seminar can be negatively affected by the noise in the adjacent room (same auditory channel), the activities of people in street traffic that is mirrored in the window pane (visual channel), and even his/her own seat that is uncomfortable and scrapes the back (tactile channel).

Therefore, it is suggested that the concept of noise also be extended. In the broader sense, noise is to be understood as all signmatter that does not come from the intended sender through the chosen channel and which disturbs the reception of the sender's signmatter, independent of the channel through which the disturbance arrives (Fiske 1982: 8). This approach suggests that, in addition to the channel-related noise level, a semiosis-related noise level has to be assumed which incorporates all channels involved. A determining factor for the success of sign reception is the number of other signs that simultaneously reach the recipient through any channel. The activities in the field of vision are just as important as sounds and smells. Semiosis-related noise is the weighted sum of the various channels' noise levels during a given sign-process. The weighting is necessary so that individual circumstances can be taken into account when drawing conclusions from semiosis-related noise about the stress for a particular person involved in a given sign-process.

Our well-being, however, depends not only on the presence or lack of stress involved in a particular sign-process. Rather, it depends on the entire situation and the signs which confront us during this situation. To identify this situation and determine its semiotic strain, one must observe the entire channel constellation for a longer period of time and not just for the duration of one sign-process. For example, a man leaves the house, sees a street lamp and the lights of the passing cars, hears the traffic sounds muted by the trees, smells the slightly musty aroma of fallen leaves, and, at the same time, feels the weight of his briefcase in his left hand. The totality of these relatively constant impressions comprise the backdrop of more specialized signprocesses which might take place between the man and his companion. Advanced semiotics should be able to determine the average overall noise level in all channels that the two persons must overcome if they are to conduct a continuous conversation.

Advanced semiotics must also be able to compare the different types of sign-production situations with regard to semiotic stress. 
What people want to say and can say to one another depends a great deal on their location: in an office in the centre of town, on a street in a large city, in a car in city traffic or on the highway, in a forest, on a beach, or in the mountains. The level of stress depends not only on the people's individual circumstances but also on the situation-specific noise in the channels. A situation-related noise level can be understood as the average overall strain produced by the noise levels in all channels during any sign-process that might take place in a given situation. Both the situation-related noise level and the individual circumstances of the persons involved are constitutive of the stress perceived in a specific situation.

As a result, these considerations charge researchers with the development of the necessary tools to operationalize and metricize the concepts of channel-related, semiosis-related, and situation-related noise. This groundwork must be laid in order to effectively measure semiotic pollution and start counteracting it.

\section{References}

Böhret, Carl 1990. Folgen: Entwurf für eine aktive Politik gegen schleichende Katastrophen. Opladen: Leske and Budrich.

Bouissac, Paul 1993. Semiotisches Wettrüsten: Zur Evolution artübergreifender Kommunikation. Zeitschrift für Semiotik 15(1/2): 3-22.

Carson, Rachel 1962. Silent Spring. Boston: Houghton Mifflin.

Cherry, Colin 1957. On Human Communication. Cambridge MA: Technology Press.

- 1967. Kommunikationsforschung: Eine neue Wissenschaft. Transl. by P. Müller. Frankfurt a.M.: S. Fischer. [1st German edition 1963.]

Dorst, Bernd 1988. Aktueller Nachtrag. In: Gourlay, Ken A., Mord am Meer. Transl. by E.v. Kardorff and G. Zelisko [German translation of Gourlay 1988.] Munich: Raben, 291-311.

Fehling, Reinhard 1976. Manipulation durch Musik: Das Beispiel "Funktionelle Musik". Munich: Raith.

Fiske, John 1982. Introduction to Communication Studies. London: Methuen.

Frank, Helmar 1969. Kybernetische Grundlagen der Pädagogik, vol. 1-2. Baden-Baden: Agis.

- 2001. Semiotik und Informationstheorie. In: Posner, R.; Robering, K.; Sebeok, T. A. (eds.), Semiotics: A Handbook on the Sign-Theoretic Foundations of Nature and Culture, vol. 3. Berlin: de Gruyter (Art. 125, in print).

Gourlay, Ken A. 1988. Poisoners of the Seas. London: Zed Books. 
Honkasalo, Antero 1996. Environmental noise as sign. Semiotica 109(1/2): 29-39.

Jerusalem, Matthias 1990. Persönliche Ressourcen, Vulnerabilität und StreßErleben. Göttingen: Hogrefe.

Koch, Ekkehard 1983. Der Weg zum blauen Himmel über der Ruhr. Essen: VGB-Kraftwerkstechnik-Verlag.

Körner, Klaus 1979. Akustische Reizüberflutung. Lilienthal bei Bremen: Eres.

Korn, Peter J. 1975. Musikalische Umweltverschmutzung. Wiesbaden: Breitkopf and Härtel. [3rd edition 1981.]

Kur, Friedrich 1986. Vom Lebens-Wandel der Lebensräume: Gefährdung, Zerstörung und Schutz von Groß- und Kleinbiotopen. Munich: dtv.

Lagadec, Patrick 1987. Das große Risiko: Technische Katastrophen und gesellschaftliche Verantwortung. Nördlingen: Greno.

Lazarus, Richard S. 1990. Theory-based stress measurement. Psychological Inquiry 1: 3-13.

Lazarus, Richard S. and Folkman, Susan 1984. Stress, Appraisal, and Coping. New York: Springer.

Loeb, Michel 1986. Noise and Human Efficiency. Chichester: Wiley.

Mayer, Horst 1979. Das Stressmodell als Erklärungsprinzip. In: Hahn, P. (ed.), Die Psychologie des 20. Jahrhunderts, vol. 9: Ergebnisse für die Medizin. Zürich: Kindler, 223-260.

Nöth, Winfried 1996. Ökosemiotik. Zeitschrift für Semiotik 18(1): 7-18.

Posner, Roland 1989. What is culture? Toward a semiotic explication of anthropological concepts. In: Koch, W. A. (ed.), The Nature of Culture. Bochum: Brockmeyer, 240-295. [German version: Was ist Kultur? Zur semiotischen Explikation anthropologischer Grundbegriffe. In: Landsch, Marle; Karnowski, H. and Bystrina, J. (eds.), 1992. Kultur-Evolution: Fallstudien und Synthese. Frankfurt a.M.: P. Lang: 1-66.]

- 1997. Pragmatics. In: Posner, R.; Robering, K.; Sebeok, T. A. (eds.), Semiotics: A Handbook on the Sign-Theoretic Foundations of Nature and Culture, vol. 1. Berlin: de Gruyter, 219-246.

- 1998. Fighting semiotic pollution in Europe: Dutch and German-speaking semiotic communities in the 20th century. In: Hess-Lüttich, Ernest W. B.; Müller, Jürgen E. and Zoest, Aart van (eds.), Culture, Sign, Space - Kultur, Zeichen, Raum: An International Conference on the Semiotics of Space and Culture in Amsterdam. Tübingen: Narr, 381-395.

Prieto, Luis J. 1966. Messages et signaux. Paris: Presses Universitaires de France.

- 1972. Nachrichten und Signale. (Transl. by G. Wotjak.) Munich: Hueber. [German translation of Prieto 1966.]

- 1975. Pertinence et pratique: Essai de sémiologie. Paris: Minuit.

Reiser, Bernhard and Mertzloff, Simone (eds.) 1988. Abfall vermeiden: Leitfaden für eine ökologische Abfallwirtschaft. Frankfurt a.M.: Fischer.

Rogge, Klaus-Eckart 1981. Physiologische Psychologie. Munich: Urban and Schwarzenberg. 
Rohrmann, Bernd 1984. Psychologische Forschung und umweltpolitische Entscheidungen: Das Beispiel Lärm. Opladen: Westdeutscher Verlag.

Schmauks, Dagmar 1997. Die Rolle des Lichts in Zeichenprozessen. Schriften der Arbeitsstelle für Semiotik 1. Berlin: Technische Universität, 1-12.

Selye, Hans 1976. The Stress of Life. New York: McGraw-Hill.

Tanner, Wilson P. 1958. What is masking? Journal of the Acoustical Society of America 30: 919-921.

Thompson, Michael 1979. Rubbish Theory: The Creation and Destruction of Value. Oxford: Oxford University Press. [In German: 1981. Die Theorie des Abfalls - Über die Schaffung und Vernichtung von Werten. Transl. by K. Schomburg. Stuttgart: Klett.]

Weizsäcker, Ernst U. von 1989. Erdpolitik: Ökologische Realpolitik an der Schwelle zum Jahrhundert der Umwelt. Darmstadt: Wissenschaftliche Buchgesellschaft. 2nd, updated edition 1990.

Wirth, Uwe 1995. Abduktion und ihre Anwendungen. Zeitschrift für Semiotik 17(3/4): 405-424.

Wolf, Winfried 1988. Eisenbahn und Autowahn: Personen- und Gütertransport auf Schiene und Straße. Zürich: Rasch.

\section{Семиотическое загрязнение: размышления об экологии знаков}

В данной статье материальное загрязнение элементарных жизненных ресурсов (воды, почвы, и воздуха) сравнивается с семиотическим загрязнением элементарных ресурсов знаковых процессов (канал, знаковая материя и сообщение; код, означающее и означаемое, а также контекст, отправитель и получатель). Утверждается, что семиотическое загрязнение сопряжено со знаковыми процессами, так же как материальное загрязнение с основными жизненными процессами; сходство этих двух типов загрязнения в том, что они вызывают стресс у людей в современных обществах. Доказывается, что семиотика способна обеспечить концептуальные инструменты для выработки мер снижения семиотического загрязнения. Однако, как показано, для операционализации и метризации обших концептов семиотического загрязнения, таких как "шум в канале связи", “семиозисный” и “ситуационный шум”, требуется дополнительное исследование. 


\section{Semiootiline saastamine: mõtisklus märkide ökoloogiast}

Antud artiklis võrreldakse elementaarsete eluressursside (vee, mulla ja õhu) materiaalset saastamist märgiliste protsesside elementaarsete ressursside (kanal, märgimateeria ja teade; kood, tähistaja ja tähistatav, aga samuti kontekst, adressaat ja adressant) semiootilise saastamisega. Väidetakse, et semiootiline saastamine on seotud märgiliste protsessidega samal moel, nagu materiaalne saastamine põhiliste eluprotsessidega nende kahe saastetüübi sarnasus seisneb selles, et mõlemad kutsuvad tänapäeva ühiskonna inimestes esile stressi. Kinnitatakse, et just semiootika on võimeline kindlustama kontseptuaalsed instrumendid, töötamaks välja vahendid semiootilise saaste vähendamiseks. Kuid semiootilise saaste üldiste kontseptide, selliste nagu "müra sidekanalis", "semioosne ja situatsiooniline müra" operatsionaliseerimiseks ja mõõdustamiseks on vajalikud täiendavad uurimused. 